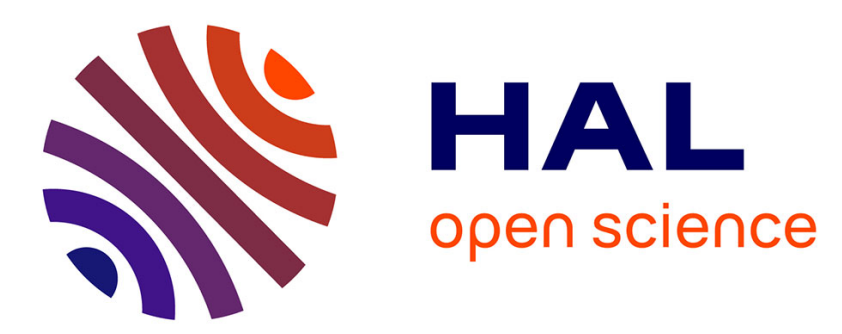

\title{
Influence of cannabis use disorder symptoms on suicidal ideation in college students
}

\author{
Henri Chabrol, Jean Chassagne, Laura Henry, Patrick Raynal
}

\section{To cite this version:}

Henri Chabrol, Jean Chassagne, Laura Henry, Patrick Raynal. Influence of cannabis use disorder symptoms on suicidal ideation in college students. International Journal of Mental Health and Addiction, 2020, 19, pp.865-871. 10.1007/s11469-019-00201-2 . hal-03192962

\section{HAL Id: hal-03192962 \\ https://hal.science/hal-03192962}

Submitted on 8 Apr 2021

HAL is a multi-disciplinary open access archive for the deposit and dissemination of scientific research documents, whether they are published or not. The documents may come from teaching and research institutions in France or abroad, or from public or private research centers.
L'archive ouverte pluridisciplinaire HAL, est destinée au dépôt et à la diffusion de documents scientifiques de niveau recherche, publiés ou non, émanant des établissements d'enseignement et de recherche français ou étrangers, des laboratoires publics ou privés. 
Influence of cannabis use disorder symptoms on suicidal ideation in college students

Henri Chabrol*, MD, Jean Chassagne, Laura Henry, Patrick Raynal

UFR de Psychologie, Université de Toulouse-Jean Jaurès, 5 allées Antonio Machado, 31058 Toulouse cedex 9, France

*Corresponding author:

H. Chabrol, UFR de Psychologie, Université de Toulouse-Jean Jaurès,

5 allées Antonio Machado, 31058 Toulouse cedex 9

phone number: +33561225290

email: henri.chabrol@univ-tlse2.fr 


\title{
CANNABIS USE AND SUICIDAL IDEATION IN COLLEGE STUDENTS
}

\begin{abstract}
The association of cannabis use and suicidal ideations in adolescents and young adults has been inconsistent. This discrepancy may reflect differences in controlled confounders but also the lack of consideration of the relationships between confounders. In particular, few studies have examined whether controlled variables mediated rather than confounded the relationship between cannabis use and suicide. Participants were 1034 college students who completed questionnaires assessing cannabis use and symptoms of cannabis use disorder (CUD), suicidal ideation, depressive and anxiety symptoms, and borderline personality traits. The dichotomic variable cannabis use versus non-use was not a significant independent predictor of suicidal ideation. Among cannabis users, the association between symptoms of CUD and suicidal ideation was significant before adjustment for confounding variables. The loss of significance of this association after control for confounders reflected the mediating effects of depressive symptoms and borderline traits on the relationship between symptoms of CUD and suicidal ideation.
\end{abstract}

Keywords: Cannabis use disorder, suicidal ideations, depressive symptoms, borderline personality traits, college students 


\section{CANNABIS USE AND SUICIDAL IDEATION IN COLLEGE STUDENTS}

\section{Introduction}

Suicidal ideation and cannabis use are associated with a multitude of shared risk factors which obscure the relationship between cannabis use and suicidal thoughts and behavior. This may explain why the association of cannabis use and suicidality in adolescents and young adults has been found to be inconsistent. Some studies reported an association between cannabis use and both suicidal ideation and attempts after adjustment for confounding variables such as depression, anxiety, alcohol abuse, other illicit drug use, deviant peer affiliations, and adverse life events (Chabrol, Chauchard, \& Girabet, 2008; Delforterie et al., 2015; Fergusson et al., 2002; Patton et al., 1997, Pedersen, 2008).

On the contrary, other studies found no association between cannabis use and suicidal ideations or attempts among high school students after controlling for confounding variables (Chabrol, Melioli, \& Goutaudier, 2014; Rasic, Kisely, \& Langille, 2011; Wilcox et al., 2010). However, these studies did not consider the possibility of mediation effects hiding the impact of cannabis use on suicidality. Price, Hemmingsson, Lewis, Zammit, and Allebeck (2009) found no association between cannabis use and increased risk of suicide after adjustment for confounders and ruled out the possibility that psychiatric diagnosis or other drug use mediated the relationship between cannabis use and suicide.

Other studies reported more ambiguous results, with some associations being found between cannabis use and suicidal thoughts or attempts, depending on the country, age or gender, frequency of use and control for confounders (Rossow, Hawton, \& Ystgaard, 2009; Silins et al., 2014; Swahn et al., 2012; van Ours, Williams, Fergusson, \& Horwood, 2013). These four studies did not examine for possible mediation effects attenuating the association between cannabis use and suicidal thoughts or behavior.

The aim of this study was to evaluate the contribution of cannabis use to suicidal ideations in a sample of college students after controlling for the main psychopathological 


\section{CANNABIS USE AND SUICIDAL IDEATION IN COLLEGE STUDENTS}

confounders and to examine possible mediation effects when confounders weaken or eliminate the relationship between cannabis use and suicidal ideation.

\section{Method}

\section{Participants and Procedure}

Participants completed an online survey which was posted on January 2018 on official websites dedicated to support groups between students and sharing groups that French universities make available to students. Each of the participants had to give their informed consent. No compensation was offered to participate in the study. The participants were provided with the possibility to contact one of the authors (PR) via email for further information or to receive referral. The study followed the guidelines of the Helsinki declaration and ethical issues of the current research were explored at a research meeting. The sample consisted of 1034 participants, 818 females (78.1\%) and 216 males (20.9\%) (mean age of females $=20.1 \pm 2$; mean age of males $=20.6 \pm 2.2$; age range $=18-30)$.

As regards the participants' fields of study, $48.5 \%$ were studying social science, $11 \%$ law, $10.5 \%$ literature, $8 \%$ science or engineering, $4 \%$ art or design, $4 \%$ medicine or paramedical studies, $3 \%$ economics, commerce, management or communication, $2 \%$ education or pedagogy, $2 \%$ history, geography or political science, $1 \%$ philosophy, $1 \%$ physical and sports activities science, $1 \%$ art history or archeology, and $4 \%$ were studying other subjects.

Internet data collection methods, using online completion of self-report questionnaires from self-selected samples, are consistent with findings from traditional methods. Internet samples are as representative of the general population than traditional samples in psychology. The data provided by Internet methods are of at least as good quality as those provided by traditional paper-and-pencil methods (Gosling, Vazire, Srivastava, \& John, 2004). 


\section{CANNABIS USE AND SUICIDAL IDEATION IN COLLEGE STUDENTS}

\section{Measures}

Cannabis use was assessed with the Cannabis Use Disorder Identification TestRevised (CUDIT-R; Adamson et al., 2010) which is an 8-item self-report screening tool and rating scale for DSM-5 cannabis use disorder (CUD) severity. The participants had to report frequency of use and how often they had been involved in the seven described behaviors during the last six months covering the symptoms of CUD (e.g., item 1: "How often do you use cannabis?"; item 4: "How often during the past 6 months did you fail to do what was normally expected from you because of using cannabis?"). Responses range from 0 (never) to 4 (4 times or more per week). Total scores vary from 0 to 32 . Higher scores indicate greater levels of symptoms of CUD. In community samples, CUDIT-R total score of 13 is a suggested cut-off for identifying possible severe cases of DSM-5 CUD (Adamson et al.; Bruno, Marshall, \& Adamson, 2013). The first item measuring frequency of use was used to differentiate cannabis users $(>0)$ and non-users $(=0)$.

Suicidal ideation was assessed using the three-item scale proposed by Garrison, Addy, Jackson, McKeown, and Waller (1991) ("I felt life was not worth living"; "I felt like hurting myself"; "I felt like killing myself"). Responses are made on a four-point scale ranging from 0 , indicating that a suicidal thought was present rarely or none of the time to 3 , indicating that a suicidal thought was present most or all of the time, over the course of the preceding week. This 3-item suicidal ideation scale showed predictive and convergent validity in previous studies (Chabrol, Chauchard, \& Girabet, 2008; Cuffe, McKeown, Addy, \& Garrison, 2005).

As confounding variables, we assessed depressive symptoms with the 9-item Personality Health Questionnaire (PHQ-9; Kroenke \& Spitzer, 2002), anxiety symptoms with the 7-item Generalized Anxiety Disorder Questionnaire (GAD-7; Spitzer, Kroenke, Williams, \& Lowe, 2006), and borderline personality traits were assessed with the borderline personality disorder scale of the Personality Diagnostic Questionnaire, Fourth Edition (PDQ-4; Hyler, 


\section{CANNABIS USE AND SUICIDAL IDEATION IN COLLEGE STUDENTS}

1994) as these psychopathological variables are strongly associated to suicidal behaviors in college students (e.g., Devi \& Prakash, 2015; Garlow et al., 2008; Jeglic, Pepper, Vanderhoff, \& Ryabchenko, 2007). Frequency of alcohol use was controlled for using the same rating scale as cannabis use frequency, since alcohol use is associated to suicidality in adolescents and young adulthood (e.g., Fergusson et al., 2002).

Cronbach's $\alpha$ values were satisfactory for all scales in the present study (Table 1).

\section{Results}

\section{Descriptive Statistics}

Among the students, $32 \%(n=330)$ used cannabis at least once during the last six months, 253 females (31\% of females) and 77 males $(36 \%)(p=.16)$. Among cannabis users, $22 \%(n=72)$ reached the CUDIT-R cut-off score of 13 for possible severe cases of DSM-5 CUD, including 49 females (19\% of female users) and 23 males (30\% of male users) ( $p=$ .04). Females reported a lower frequency of use than males: average use for females was slightly lower than 2-4 times whereas average use for males was slightly higher than 2-4 times a month $(1.83 \pm 1.28$ vs. $2.18 \pm 1.35, t=2.07, p=.04)$. Female users had lower levels of symptoms of CUD than males $(6.90 \pm 5.65$ vs $8.79 \pm 6.61, p<.05)$.

The frequency of the wish to kill oneself occurring at least some of the time was $13 \%$ in female users, $7 \%$ in male users, $10 \%$ in female non-users, and $11 \%$ in male non-users. There were no statistically significant differences between female and male users $(p=.10)$, female and male non-users $(p=.66)$, female users and non-users $(p=.17)$, male users and non-users $(p=.32)$.

\section{Correlations between Variables}

Among cannabis users, anxiety and depressive symptoms, and borderline personality disorder traits were moderately correlated with suicidal ideation. Symptoms of CUD were positively modestly correlated to suicidal ideation (Table 1). 
CANNABIS USE AND SUICIDAL IDEATION IN COLLEGE STUDENTS

\section{Multiple Regression Analysis Predicting Suicidal Ideation}

Firstly, in the total sample, we conducted a multiple regression analysis predicting suicidal ideation with gender, age and cannabis use vs. non-use. Age was the only significant predictor $(\beta=-.09, p=.005)$. Cannabis use was not significantly associated to suicidal ideation $(\beta=.05, p=.12)$.

Among users, a hierarchical multiple regression analysis was conducted to identify unique associations between suicidal ideation and gender, age, and all variables significantly correlated to suicidal ideation. A square root transformation was conducted on CUDIT score to reduce skewness. All predictor variables had tolerance values $>0.4$ excluding multicollinearity. The proportion of the variance in suicidal ideation explained by the predictors was reported with the multiple $R^{2}$. The unique contribution of each predictor was reported with standardized regression coefficient $(\beta), t$ and $p$ value.

In the first step of this analysis, gender, age, and symptoms of CUD were entered. Symptoms of CUD were a significant predictor (Table 2).

In the second step, psychopathological variables were entered. Depressive symptoms and borderline traits were significantly associated to suicidal ideation. Symptoms of CUD were no longer significantly related to suicidal ideations, suggesting a perfect mediation effect of depressive symptoms and borderline traits on the relationship between problematic use symptoms and suicidal ideation (Table 2). Symptoms of CUD were significant predictors of both depressive symptoms $\left(R^{2}=.02, \beta=.14, p=.01\right)$ and borderline traits $\left(R^{2}=.03, \beta=.19\right.$, $p<.001)$. Sobel tests in which the other mediator was controlled confirmed indirect effects via depressive symptoms, $z=2.26, p=.01$, and via borderline traits, $z=2.17, p=.015$.

\section{Discussion}

This study found that levels of suicidal ideation were similar among cannabis users and non-users and that the dichotomic variable cannabis use vs. non use was not a significant 


\section{CANNABIS USE AND SUICIDAL IDEATION IN COLLEGE STUDENTS}

predictor of suicidal ideation among French college students. Among users, the level of symptoms of CUD was significantly associated to suicidal ideation, but the control of depressive symptoms and borderline traits eliminated this association, suggesting complete mediation effects that were confirmed. These mediation effects might suggest that symptoms of CUD could increase depressive symptoms and borderline traits, and influence suicidal ideation indirectly through increasing psychopathological symptoms. This possibility is consistent with studies reporting that cannabis use may be associated with an increased risk for developing depressive disorders particularly in youth (Leadbeater, Ames, \& LindenCarmichael, 2019; Lev-Ran et al., 2014) and may slow the normative decline in BPD traits from mid-adolescence into young adulthood (Bornovalova et al., 2018).

The lack of significant association between symptoms of CUD and suicidality might reflect hidden mediation effects of confounders and could not be interpreted as no influence of cannabis use on suicidal thoughts and behavior. The impact of cannabis use may be indirect through psychopathological variables or social variables such as social isolation which is a risk factor for suicidality and may be a consequence of symptoms of CUD in young adults (e.g., Kandel, Davies, Karus, \& Yamaguchi, 1986; Ploskonka \& Servaty-Seib, 2015).

This study has several limitations. As the study was conducted in a community sample, the results cannot be generalized to clinical samples. If mediation analyses can invite inferences about temporal relations, that may not be justified with cross-sectional data which preclude causal interpretation. Another limitation is the limited number of confounders used in this study. However, they were sufficient to eliminate the association between symptoms of CUD and suicidal ideation to test for mediation effects.

This study suggests that the link between cannabis use and suicidal ideation may be obscured in study adjusting for risk factors of suicidal ideation as some of them may be mediators fully eliminating the association between cannabis use and suicidal ideation. 


\section{CANNABIS USE AND SUICIDAL IDEATION IN COLLEGE STUDENTS}

Research protocols exploring the relationship between cannabis use and suicidality among young adults should examine for possible mediation effects that could mask the influence of cannabis use on suicidality.

\section{Acknowledgements}

This study was not funded by any organization.

\section{Compliance with Ethical Standards}

\section{Declaration of interest}

Henri Chabrol, Jean Chassagne, Laura Henry, and Patrick Raynal declare that they have no conflict of interest.

\section{Informed Consent}

All participants took part voluntarily and were informed about the objectives of the study.

\section{Ethical Approval}

All procedures performed in this study were in accordance with the ethical standards of the university's research ethics committee and with the Helsinki Declaration of 1975, as revised in 2000 .

\section{References}

Adamson, S. J., Kay-Lambkin, F. J., Baker, A. L., Lewin, T. J., Thornton, L., Kelly, B. J., \& Sellman, J. D. (2010). An improved brief measure of cannabis misuse: the Cannabis Use Disorders Identification Test-Revised (CUDIT-R). Drug and Alcohol Dependence, 110, 137-143. doi:10.1016/j.drugalcdep.2010.02.017 


\section{CANNABIS USE AND SUICIDAL IDEATION IN COLLEGE STUDENTS}

Bornovalova, M. A., Verhulst, B., Webber, T., McGue, M., Iacono, W. G., \& Hicks, B. M. (2018). Genetic and environmental influences on the codevelopment among borderline personality disorder traits, major depression symptoms, and substance use disorder symptoms from adolescence to young adulthood. Development and Psychopathology, 30, 49-65. doi:10.1017/S0954579417000463

Bruno, R., Marshall, S., \& Adamson, S. (2013). Screening for DSM-5 cannabis dependence using the Cannabis Use Identification Test-Revised (CUDIT-R). Poster presented at the Australasian Professional Society on Alcohol and other Drugs.

Chabrol, H., Chauchard, E., \& Girabet, J. (2008). Cannabis use and suicidal behaviors in high-school students. Addictive Behaviors, 33, 152-155.

doi:10.1016/j.addbeh.2007.04.029

Cuffe, S. P., McKeown, R. E., Addy, C. L., \& Garrison, C. Z. (2005). Family and psychosocial risk factors in a longitudinal epidemiological study of adolescents. Journal of the American Academy of Child \& Adolescent Psychiatry, 44, 121-129. doi:10.1097/00004583-200502000-00004

Delforterie, M. J., Lynskey, M. T., Huizink, A. C., Creemers, H. E., Grant, J. D., Few, L. R., ... \& Madden, P. A. (2015). The relationship between cannabis involvement and suicidal thoughts and behaviors. Drug and Alcohol Dependence, 150, 98-104. doi :10.1016/j.drugalcdep.2015.02.019

Devi, W. R., \& Prakash, J. (2015). Anxiety: An Independent Potential Risk Factor for Suicidal Ideation among College Students. International Journal of Psychology and Psychiatry, 3, 92-105. doi:10.5958/2320-6233.2015.00019.X

Fergusson, D.M., Horwood, L.J., \& Swain-Campbell, N. (2002). Cannabis use and psychosocial adjustment in adolescence and young adulthood. Addiction, 97, 1121135. doi: 10.1046/j.1360-0443.2002.00103.x 


\section{CANNABIS USE AND SUICIDAL IDEATION IN COLLEGE STUDENTS}

Garlow, S. J., Rosenberg, J., Moore, J. D., Haas, A. P., Koestner, B., Hendin, H., \& Nemeroff, C. B. (2008). Depression, desperation, and suicidal ideation in college students: results from the American Foundation for Suicide Prevention College Screening Project at Emory University. Depression and Anxiety, 25, 482-488. doi:10.1002/da.20321

Garrison, C. Z., Addy, C. L., Jackson, K. L., McKeown, R. E., \& Waller, J. L. (1991). A longitudinal study of suicidal ideation in young adolescents. Journal of the American Academy of Child \& Adolescent Psychiatry, 30, 597-603. doi:10.1097/00004583199107000-00011

Hyler, S. E. (1994). Personality Questionnaire (PDQ-4+). New York State Psychiatric Institute: New York.

Jeglic, E. L., Pepper, C. M., Vanderhoff, H. A., \& Ryabchenko, K. A. (2007). An analysis of suicidal ideation in a college sample. Archives of Suicide Research, 11, 41-56. doi:10.1080/13811110600897176

Kandel, D. B., Davies, M., Karus, D., \& Yamaguchi, K. (1986). The Consequences in Young Adulthood of Adolescent Drug Involvement: An Overview. Archives of General Psychiatry, 43, 746-754. doi:10.1001/archpsyc.1986.01800080032005

Leadbeater, B. J., Ames, M. E., \& Linden-Carmichael, A. N. (2019). Age-varying effects of cannabis use frequency and disorder on symptoms of psychosis, depression and anxiety in adolescents and adults. Addiction, 114(2), 278-293.

Lev-Ran, S., Roerecke, M., Le Foll, B., George, T. P., McKenzie, K., \& Rehm, J. (2014). The association between cannabis use and depression: a systematic review and metaanalysis of longitudinal studies. Psychological Medicine, 44(4), 797-810.

doi:10.1017/S0033291713001438 


\section{CANNABIS USE AND SUICIDAL IDEATION IN COLLEGE STUDENTS}

Patton, G.C., Harris, R., Carlin, J.B., Hibbert, M.E., Coffey, C., Schwartz, M., ...\& Bowes, G. (1997). Adolescent suicidal behaviours: a population-based study of risk. Psychological Medicine, 27, 715-724. doi:10.1017/S003329179600462X

Pedersen, W. (2008). Does cannabis use lead to depression and suicidal behaviours? A population-based longitudinal study. Acta Psychiatrica Scandinavica, 118, 395-403. doi:10.1111/j.1600-0447.2008.01259

Ploskonka, R. A., \& Servaty-Seib, H. L. (2015). Belongingness and suicidal ideation in college students. Journal of American College Health, 63, 81-87. doi:10.1080/07448481.2014.983928

Price, C., Hemmingsson, T., Lewis, G., Zammit, S., \& Allebeck, P. (2009). Cannabis and suicide: longitudinal study. The British Journal of Psychiatry, 195(6), 492-497. doi: 10.1192/bjp.bp.109.065227

Rasic, D., Kisely, S., \& Langille, D. B. (2011). Protective associations of importance of religion and frequency of service attendance with depression risk, suicidal behaviours and substance use in adolescents in Nova Scotia, Canada. Journal of Affective Disorders, 132, 389-395. doi:10.1016/j.drugalcdep.2012.09.009

Rossow, I., Hawton, K., \& Ystgaard, M. (2009). Cannabis use and deliberate self-harm in adolescence: a comparative analysis of associations in England and Norway. Archives of Suicide Research, 13, 340-348. doi:10.1080/13811110903266475

Sharp, C., Green, K. L., Yaroslavsky, I., Venta, A., Zanarini, M. C., \& Pettit, J. (2012). The incremental validity of borderline personality disorder relative to major depressive disorder for suicidal ideation and deliberate self-harm in adolescents. Journal of Personality Disorders, 26, 927-938. doi:10.1521/pedi.2012.26.6.927

Silins, E., Horwood, L. J., Patton, G. C., Fergusson, D. M., Olsson, C. A., Hutchinson, D. M., ... \& Coffey, C. (2014). Young adult sequelae of adolescent cannabis use: an 


\section{CANNABIS USE AND SUICIDAL IDEATION IN COLLEGE STUDENTS}

integrative analysis. The Lancet Psychiatry, 1, 286-293. doi:10.1016/S2215-

0366(14)70307-4

Swahn, M. H., Bossarte, R. M., Choquet, M., Hassler, C., Falissard, B., \& Chau, N. (2012).

Early substance use initiation and suicide ideation and attempts among students in France and the United States. International Journal of Public Health, 57, 95-105. doi: 10.1007/s00038-011-0255-7.

van Ours, J.C., Williams, J., Fergusson, D., \& Horwood, L.J.(2013). Cannabis use and suicidal ideation. Journal of Health Economics, 32, 524-537. doi:

10.1016/j.jhealeco.2013.02.002

Wilcox, H. C., Arria, A. M., Caldeira, K. M., Vincent, K. B., Pinchevsky, G. M., \& O'Grady, K. E. (2010). Prevalence and predictors of persistent suicide ideation, plans, and attempts during college. Journal of Affective Disorders, 127, 287-294.

doi :10.1016/j.jad.2010.04.017 
Table 1 - Correlations Between all Variables Among Cannabis Users $(N=330)$.

\begin{tabular}{lcccccc} 
& 1 & 2 & 3 & 4 & 5 & 6 \\
\hline 1- Suicidal Ideations & & & & & & \\
2- Symptoms of CUD & $.14^{* *}$ & & & & & \\
3- Age & $-.14^{* *}$ & -0.04 & & & & \\
4- Gender & -0.32 & $.14^{*}$ & $.35^{* *}$ & & & \\
5- Anxiety symptoms & $.48^{* *}$ & 0.06 & -0.1 & $-.12^{*}$ & & \\
6- Depressive symptoms & $.59^{* *}$ & $.15^{* *}$ & $-.21^{* *}$ & -0.02 & $.67 * *$ & \\
7- Borderline traits & $.56^{* *}$ & $.19^{* *}$ & $-.29 * *$ & $-.11^{*}$ & $.60^{* *}$ & $.68^{* *}$ \\
\hline
\end{tabular}

Note : *p<.05**p<.01

CUD $=$ Cannabis Use Disorder 
Table 2 - Hierarchical Regression Analysis Predicting Suicidal Ideation Among Cannabis Users $(N=330)$.

\begin{tabular}{lccccc}
\hline & $\boldsymbol{F}$ & $\boldsymbol{\Delta \boldsymbol { R } ^ { 2 }}$ & $\boldsymbol{\beta}$ & $\boldsymbol{t}$ & $\boldsymbol{p}$ \\
\cline { 2 - 6 } Step 1 & $4.45^{*}$ & .04 & & & 0.253 \\
Age & & & -.14 & -2.33 & .02 \\
Gender & & & -.004 & -.07 & .94 \\
Symptoms of CUD & & & .14 & 2.51 & .01 \\
Step 2 & $36.55^{* *}$ & .40 & & & \\
Age & & & .02 & 5.64 & .68 \\
Gender & & & .001 & -1.81 & .98 \\
Symptoms of CUD & & & .03 & .75 & .45 \\
Anxiety symptoms & & & .08 & 1.23 & .22 \\
Depressive symptoms & & & .35 & 5.35 & $<.0001$ \\
Borderline traits & & & .28 & 4.43 & $<.0001$ \\
\hline
\end{tabular}

Note : ${ }^{*} p<.01{ }^{* *} p<.001$.

CUD $=$ Cannabis Use Disorder 